\title{
Regulation of Regenerative Periodontal Healing by NAMPT
}

\author{
Marjan Nokhbehsaim, ${ }^{1,2}$ Sema Keser, ${ }^{2}$ Andreas Jäger, ${ }^{2,3}$ \\ Søren Jepsen, ${ }^{2,4}$ and James Deschner ${ }^{1,2}$ \\ ${ }^{1}$ Experimental Dento-Maxillo-Facial Medicine, Center of Dento-Maxillo-Facial Medicine, University of Bonn, 53111 Bonn, Germany \\ ${ }^{2}$ Clinical Research Unit 208, Center of Dento-Maxillo-Facial Medicine, University of Bonn, Welschnonnenstraße 17, \\ 53111 Bonn, Germany \\ ${ }^{3}$ Department of Orthodontics, University of Bonn, 53111 Bonn, Germany \\ ${ }^{4}$ Department of Periodontology, Operative and Preventive Dentistry, University of Bonn, 53111 Bonn, Germany
}

Correspondence should be addressed to James Deschner; james.deschner@uni-bonn.de

Received 29 May 2013; Revised 30 August 2013; Accepted 13 September 2013

Academic Editor: Peter Plomgaard

Copyright (C) 2013 Marjan Nokhbehsaim et al. This is an open access article distributed under the Creative Commons Attribution License, which permits unrestricted use, distribution, and reproduction in any medium, provided the original work is properly cited.

\begin{abstract}
Periodontitis is an inflammatory disease characterized by destruction of the tooth-supporting tissues. Obese individuals have an increased risk of periodontitis, and elevated circulating levels of nicotinamide phosphoribosyltransferase (NAMPT) may be a pathomechanistic link between both diseases. Recently, increased levels of NAMPT have also been found in patients with periodontitis, irrespective of the presence of obesity. This in vitro study sought to examine the effects of NAMPT on the regenerative capacity of human periodontal ligament (PDL) cells and, thereby, periodontal healing. PDL cells treated with enamel matrix derivative (EMD), which was used to mimic regenerative healing conditions in vitro, were grown in the presence and absence of NAMPT for up to $14 \mathrm{~d}$. EMD stimulated significantly $(P<0.05)$ the expression of growth factors and their receptors, matrix molecules, osteogenesis-associated factors, and wound closure and calcium accumulation. In the presence of NAMPT, all these stimulatory effects were significantly $(P<0.05)$ reduced. In conclusion, the beneficial effects of EMD on a number of PDL cell functions critical for periodontal regeneration are counteracted by NAMPT. Enhanced levels of NAMPT, as found in obesity and periodontal inflammation, may compromise the regenerative capacity of PDL cells and, thereby, periodontal healing in the presence of EMD.
\end{abstract}

\section{Introduction}

Periodontitis is a chronic multifactorial inflammatory disease that is characterized by the progressive destruction of the tooth-supporting tissues, such as the periodontal ligament (PDL). Pathogenic microorganisms embedded in a biofilm on the tooth surface can trigger local synthesis of proinflammatory mediators and matrix-degrading proteases by infiltrating and resident cells of the periodontium. As a consequence of the exaggerated immunoinflammatory and proteolytic processes, the periodontal tissues are subjected to degradation and resorption, which can result in periodontal pocket formation and even tooth loss [1-4]. The National Health and Nutrition Examination Survey III that analyzed the health and nutritional status in the United States revealed that approximately half of the US population aged $\geq 30$ years suffers from periodontitis [5]. It is widely accepted that periodontitis has a significant negative impact on physical, psychological, and social aspects of life and also affects systemic health in affected individuals [6-8].

The main goal of periodontal therapy is to arrest the inflammatory and tissue-destructive processes by reducing or eliminating the pathogenic microorganisms in the periodontal pockets [9]. Conventional periodontal treatment comprises nonsurgical or surgical debridement, sometimes applied in combination with antibiotics, and achieves periodontal healing mainly by repair [10]. Regenerative healing can be stimulated by the application of bioactive molecules, such as enamel matrix derivative (EMD), during periodontal surgery [11-13]. A great number of in vitro studies have demonstrated that EMD stimulates the synthesis of growth factors, such as vascular endothelial growth factor (VEGF) 
and transforming growth factor (TGF) $\beta 1$, matrix molecules, such as collagen type I (COL1) and periostin (POSTN), osteogenesis-related factors, such as runt-related transcription factor (RUNX) 2, calcium deposition, and in vitro wound healing $[14,15]$. It is widely accepted that the regenerationpromoting activities of EMD are induced at least in part by these mechanisms. Moreover, it has been shown that the beneficial effects of EMD on periodontal regeneration are mediated, at least partially, by bone morphogenetic protein (BMP) and TGF $\beta$, because fractions of EMD contain BMPand TGF $\beta$-like activity and EMD stimulates BMP and TGF $\beta$ synthesis in periodontal cells [16-19]. Binding of TGF $\beta$ and $\mathrm{BMP}$ to their receptor complexes triggers SMAD (sma- and mad-related protein) and non-SMAD signaling cascades [20, 21].

Regeneration of periodontal tissues is often an unpredictable challenge due to a number of as yet unidentified local and systemic factors that can modulate healing processes. Previous studies suggest that microbial, inflammatory, and biomechanical signals can interfere with the beneficial effects of EMD on periodontal cells, emphasizing the critical role of the cell environment for optimal periodontal regeneration [22-27]. In addition, recent meta-analyses have revealed that obesity, metabolic syndrome, and diabetes mellitus are significantly associated with periodontitis, and it has been suggested that adipokines might be a critical pathomechanistic link in these associations [28-31]. Adipokines are cytokines released from the adipose tissue and regulate food intake and energy expenditure but also immunoinflammatory processes $[32,33]$. Since the serum levels of a number of proinflammatory adipokines, such as nicotinamide phosphoribosyltransferase (NAMPT), are increased in obesity and some obesity-related diseases, it has been speculated that such adipokines could enhance periodontal inflammation and, thereby, increase the risk of periodontitis or compromise periodontal healing in obese individuals [34-38].

NAMPT is mainly produced by macrophages and adipocytes in the adipose tissue, triggers $\mathrm{NF} \kappa \mathrm{B}$ activation, and elicits synthesis of inflammatory mediators [39]. Increased serum levels of NAMPT have been found in obesity, metabolic syndrome, type 2 diabetes, atherosclerosis, and other diseases [34-36]. Therefore, elevated NAMPT levels could be one mechanism, whereby these diseases contribute to the initiation and progression of periodontitis. Interestingly, NAMPT is also present at high levels in gingival crevicular fluid (GCF), gingival tissues, and serum from patients afflicted with periodontitis, irrespective of the presence of obesity [40-42]. These observations indicate that NAMPT is also produced locally in the periodontium and may play a role in the etiopathogenesis of periodontitis. Our previous experiments have demonstrated that periodontal pathogens upregulate NAMPT in periodontal cells and, additionally, that NAMPT could contribute to periodontal inflammation and destruction by stimulating periodontal cells to produce proinflammatory and proteolytic molecules $[43,44]$. However, whether NAMPT also interferes with periodontal healing is as yet unknown. Therefore, this in vitro study sought to examine whether the regenerative capacity of periodontal cells in the presence of EMD is modulated by
NAMPT. A better understanding of the interactions between regenerative molecules and local as well as systemic factors may help better predict and even improve the outcome of currently applied periodontal treatment approaches.

\section{Materials and Methods}

2.1. Culture and Treatment of Cells. PDL cells from 18 periodontally healthy donors, who underwent tooth extraction for orthodontic reasons, were used for the experiments. Informed consent and approval of the Ethics Committee of the University of Bonn were obtained. The cells were grown in Dulbecco's minimal essential medium (DMEM, Invitrogen, Karlsruhe, Germany) supplemented with $10 \%$ fetal bovine serum (FBS, Invitrogen), 100 units penicillin, and $100 \mu \mathrm{g} / \mathrm{mL}$ streptomycin (Invitrogen) at $37^{\circ} \mathrm{C}$ in a humidified atmosphere of $5 \% \mathrm{CO}_{2}$. Cells between $3 \mathrm{rd}$ and 5 th passage were seeded $(50,000$ cells/well) on culture plates and grown to $80 \%$ confluence. One day prior to the experiments, the FBS concentration was reduced to $1 \%$. Medium was changed every second day. In order to simulate regenerative conditions in vitro, PDL cells were treated with EMD (Emdogain, Straumann, Freiburg, Germany) in the presence and absence of NAMPT. As in our previous studies, EMD was applied at a concentration of $100 \mu \mathrm{g} / \mathrm{mL}$ because this concentration had been used by several investigators before and ensured that our data were comparable with those of other studies [2427]. In order to investigate the effects of NAMPT, various concentrations of this adipokine $(30,100$, and $300 \mathrm{ng} / \mathrm{mL}$; Biomol, Hamburg, Germany) were added to cells. In our experiments, the standard concentration of NAMPT was $100 \mathrm{ng} / \mathrm{mL}$. This concentration correlates well with the studies by Pradeep and coworkers, who have reported a NAMPT concentration of $98.32 \mathrm{ng} / \mathrm{mL}$ in gingival crevicular fluid [4042]. However, these studies only included a small number of patients, so that even higher concentrations can be expected in some individuals and were therefore also studied in a subset of our experiments. In the present study, cells were exposed to EMD and/or NAMPT for up to $14 \mathrm{~d}$ (Figure 1). In order to analyze the intracellular mechanisms used by NAMPT to modulate the actions of EMD, cells were preincubated with specific inhibitors against $\mathrm{NF} \kappa \mathrm{B}$ (pyrrolidine dithiocarbamate, PDTC; $10 \mu \mathrm{M}$; Calbiochem, San Diego, CA, USA), MEK1/2 (U0126; $10 \mu \mathrm{M}$; Calbiochem), JNK (SP600125; $10 \mu \mathrm{M}$; Calbiochem), and p38 (SB203580; $10 \mu \mathrm{M}$; Calbiochem) signaling pathways $1 \mathrm{~h}$ before experiments.

2.2. Real-Time PCR. RNA was extracted by using an RNA extraction kit (Qiagen, Hilden, Germany), and a total of $1 \mu \mathrm{g}$ of RNA was reverse transcribed using iScriptTM Select cDNA Synthesis Kit (Bio-Rad Laboratories, Munich, Germany) at $42^{\circ} \mathrm{C}$ for $90 \mathrm{~min}$ followed by $85^{\circ} \mathrm{C}$ for $5 \mathrm{~min}$. Expression of VEGF, TGF $\beta 1$, and its receptor TGF $\beta$ R2, BMP receptors (BMPR1A, BMPR1B, and BMPR2), COL1, POSTN, and RUNX2 was detected by real-time PCR using the iCycler iQ detection system (Bio-Rad Laboratories), SYBR Green (BioRad Laboratories), and specific primers (QuantiTect Primer Assay, Qiagen) (Figure 1). One $\mu \mathrm{L}$ of cDNA was amplified as 


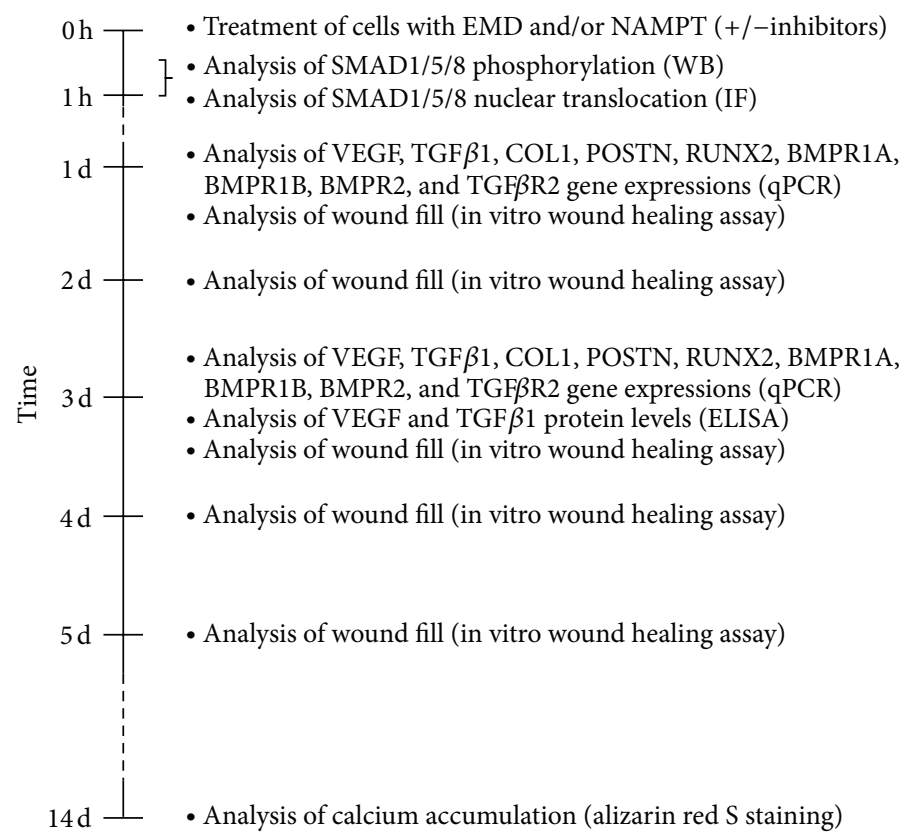

FIGURE 1: Study design flowchart. EMD: enamel matrix derivative; NAMPT: nicotinamide phosphoribosyltransferase; SMAD: sma- and madrelated protein; WB: western blot; IF: immunofluorescence; VEGF: vascular endothelial growth factor; TGF $\beta 1$ : transforming growth factor $\beta 1$; COL1: collagen type I; POSTN: periostin; RUNX2: runt-related transcription factor 2; BMPR1A, 1B, or 2: bone morphogenetic protein receptor $1 \mathrm{~A}, 1 \mathrm{~B}$, or 2; TGF $\beta \mathrm{R} 2$ : TGF $\beta$ receptor 2; qPCR: quantitative polymerase chain reaction; ELISA: enzyme-linked immunosorbent assay.

a template in a $25 \mu \mathrm{L}$ reaction mixture containing $12.5 \mu \mathrm{L} 2 \mathrm{x}$ QuantiFast SYBR Green PCR Master Mix (Qiagen), $2.5 \mu \mathrm{L}$ of primers, and $9 \mu \mathrm{L}$ deionized water. The mixture was heated initially at $95^{\circ} \mathrm{C}$ for $5 \mathrm{~min}$ and then followed by 40 cycles with denaturation at $95^{\circ} \mathrm{C}$ for $10 \mathrm{~s}$ and combined annealing/extension at $60^{\circ} \mathrm{C}$ for $30 \mathrm{~s}$. Glyceraldehyde-3-phosphate dehydrogenase was used as an endogenous control. The data were analyzed by the comparative threshold cycle method.

2.3. ELISA. The protein levels of VEGF and TGF $\beta 1$ in the supernatants of PDL cells were analysed by commercially available enzyme-linked immunosorbent assay (ELISA) kits (R\&D Systems, Minneapolis, MN, USA) according to the manufacturer's instructions (Figure 1). The absorbance was measured by using a microplate reader (PowerWave x, BioTek Instruments, Winooski, VT, USA) at $450 \mathrm{~nm}$. The data were normalized by cell number that was determined with an automatic cell counter (Moelab, Hilden, Germany).

2.4. Alizarin Red S Staining. The calcium accumulation in PDL cell cultures following $14 \mathrm{~d}$ of treatment with EMD and/or NAMPT was analyzed by using alizarin red S staining (Merck KGaA, Darmstadt, Germany) and cetylpyridinium chloride (Sigma-Aldrich Chemie, Munich, Germany), as described in our previous studies (Figure 1) [24, 25]. Briefly, cell monolayers were washed with PBS, fixed in $4 \%$ paraformaldehyde (Merck KGaA) for $10 \mathrm{~min}$, and washed again with deionized water. Afterwards, cells were incubated with $40 \mathrm{mM}$ alizarin red $\mathrm{S}(\mathrm{pH} 4.2)$ for $15 \mathrm{~min}$, rinsed with deionized water, and subsequently incubated with $10 \%$ (w/v) cetylpyridinium chloride in $10 \mathrm{mM}$ sodium phosphate
( $\mathrm{pH} 7.0$ ) in order to extract the alizarin red $\mathrm{S}$ that was retained in the cell cultures. Following $15 \mathrm{~min}$ of incubation, cells were detached from the well surface. The detached cells and cetylpyridinium chloride were collected and centrifuged at $20,000 \mathrm{~g}$ for $10 \mathrm{~min}$. Afterwards, the pellets were discarded and the supernatants that contained the extracted stain were transferred into a 96-well plate to analyze the absorbance at $562 \mathrm{~nm}$ using a microplate reader.

2.5. In Vitro Wound Healing. In order to examine the effect of NAMPT on wound fill, an in vitro wound healing model was used, as in our previous experiments [24, 25]. Briefly, cells were grown until confluence and $3 \mathrm{~mm}$ wide wounds were created in a standardized manner in the cell monolayers. The wounded cell monolayers were treated with EMD and, simultaneously, with various concentrations of NAMPT $(0$, 30,100 , and $300 \mathrm{ng} / \mathrm{mL}$ ) for $5 \mathrm{~d}$. At every day, the wounds were documented by inverse microscopy (Axiovert $25 \mathrm{C}$, $5 \mathrm{x}$ objective, Carl Zeiss, Oberkochen, Germany) and digital photography (Kodak DC 290, Kodak, Stuttgart, Germany) (Figure 1). Measurement and analysis of the wound widths were performed with special software (Alpha DigiDoc 1000, Alpha Innotech, San Leandro, CA).

2.6. Immunofluorescence. PDL cells were fixed with $4 \%$ paraformaldehyde in PBS $\mathrm{pH} 7.4$ for $10 \mathrm{~min}$, washed with PBS, and treated with $0.1 \%$ Triton X-100 (Sigma-Aldrich, Munich, Germany) for $5 \mathrm{~min}$. Then, cells were washed again and blocked with nonfat dry milk (Bio-Rad Laboratories) for 1h. After washing, cells were incubated with a rabbit antiSMAD1/5/8 antibody (Santa Cruz Biotechnology, Santa Cruz, 
CA, Germany) for $90 \mathrm{~min}$ and with CY3-conjugated goat anti-rabbit IgG (Abcam, Cambridge, MA, USA) for $45 \mathrm{~min}$. Cells were observed under a 20x objective using an Axioplan 2 imaging microscope (Carl Zeiss). The images were captured with a PVCAM camera and the VisiView capturing software (Visitron Systems, Puchheim, Germany) (Figure 1).

2.7. Western Blot Analysis. Phosphorylation of SMAD1/5/8 was analyzed from whole lysate (20 to $40 \mu \mathrm{g}$ protein) of cells treated with EMD in the presence or absence of NAMPT (Figure 1). Cells were washed twice with ice cold PBS and collected in RIPA buffer (Sigma-Aldrich) supplemented with protease inhibitors (Sigma-Aldrich). Equal amounts of protein were resolved through SDS-polyacrylamide gel electrophoresis and transferred to nitrocellulose membranes (Bio-Rad Laboratories). The membranes blocked with 5\% nonfat milk were probed with a specific rabbit antipSMAD1/5/8 antibody (Cell Signalling Technology, Danvers, MA, USA). The binding of the primary antibody was revealed with horseradish peroxidase- (HRP-) labeled goat anti-rabbit IgG (Jackson ImmunoResearch, Suffolk, UK). Lightning chemiluminescence reagent (Thermo Fisher Scientific, Rockford, IL, USA) was used as an HRP substrate. All blots were reprobed with rabbit anti-SMAD1/5/8 (Santa Cruz Biotechnology) and mouse anti- $\beta$-actin antibodies (abcam, Cambridge, UK) to assure equal input of proteins.

2.8. Statistical Analysis. All experiments were performed in triplicate and repeated at least twice. Mean values and standard errors of the mean (SEM) were calculated. Parametric ( $t$ test and ANOVA followed by the post hoc Tukey's test) and nonparametric tests (Wilcoxon and Mann-Whitney $U$ tests) were applied for statistical analysis by using the IBM SPSS Statistics 20 software. Differences between groups were considered significant at $P<0.05$.

\section{Results}

3.1. Regulation of EMD Effects on Growth Factors by NAMPT. Since the regeneration-promotive effects of EMD are at least partly mediated by upregulation of growth factors, we first sought to determine whether these EMD actions on PDL cells are modulated by NAMPT. As expected from previous studies, EMD caused a significant upregulation of VEGF and TGF $\beta 1$ in PDL cells at $1 \mathrm{~d}$ and $3 \mathrm{~d}$. However, the EMD-stimulated VEGF und TGF $\beta 1$ expressions were significantly reduced in the presence of NAMPT at both time points, as shown in Figures 2(a) and 2(b). Interestingly, NAMPT did not induce a significant downregulation of the constitutive VEGF and TGF $\beta 1$ expressions (Figures 2(a) and 2(b)). Dose response experiments revealed that the inhibitory effects of NAMPT on the EMD-stimulated VEGF and TGF $\beta 1$ upregulation were similar over a wide range of concentrations (Figures 2(c) and 2(d)). By preincubation of cells with a specific inhibitor against the JNK signaling pathway, the inhibitory effects of NAMPT on the EMD-induced VEGF and TGF $\beta 1$ expressions were completely blocked at $1 \mathrm{~d}$. However, inhibition of $\mathrm{NF} \kappa \mathrm{B}, \mathrm{MEK} 1 / 2$, or p38 signaling did
TABLE 1: Regulation of VEGF and TGF $\beta 1$ protein syntheses by EMD and/or NAMPT ( $100 \mathrm{ng} / \mathrm{mL})$ after $3 \mathrm{~d}$, as analyzed by ELISA. Untreated cells served as control. Mean \pm SEM $(n=12) ;{ }^{*}$ significantly $(P<0.05)$ different from all other groups.

\begin{tabular}{lcc}
\hline Group & $\begin{array}{c}\text { VEGF } \\
\left(\mathrm{ng} / 10^{6} \text { cells }\right)\end{array}$ & $\begin{array}{c}\text { TGF } \beta 1 \\
\left(\mathrm{ng} / 10^{6} \text { cells }\right)\end{array}$ \\
\hline Control & $1.68 \pm 0.08$ & $2.08 \pm 0.01$ \\
EMD & $3.88 \pm 0.32^{*}$ & $3.39 \pm 0.11^{*}$ \\
NAMPT & $1.73 \pm 0.01$ & $1.68 \pm 0.02$ \\
EMD + NAMPT & $3.07 \pm 0.34$ & $2.78 \pm 0.06$ \\
\hline
\end{tabular}

not interfere with the actions of NAMPT at this time point (data not shown).

The inhibitory effects of NAMPT on the EMD-stimulated VEGF and TGF $\beta 1$ expressions were also found at protein level, as analyzed by ELISA after $3 \mathrm{~d}$ (Table 1).

3.2. Modulation of EMD Actions on Matrix Molecules by NAMPT. EMD also stimulates periodontal regeneration by upregulation of matrix molecules. Therefore, we next studied whether actions of EMD on matrix molecules are modulated by NAMPT. EMD increased significantly the expression of COL1 and POSTN at $1 \mathrm{~d}$ and $3 \mathrm{~d}$, but these stimulatory effects were significantly inhibited by NAMPT for COL1 at $1 \mathrm{~d}$ and for POSTN at $1 \mathrm{~d}$ and $3 \mathrm{~d}$ (Figures 2(e) and 2(f)). NAMPT had no regulatory effects on the spontaneous expression of COL1 and POSTN (Figures 2(e) and 2(f)).

3.3. Effects of NAMPT on EMD-Stimulated Mineralization. Next, we wondered whether NAMPT would also interfere with the stimulatory effects of EMD on osteogenesis. As expected, EMD stimulated significantly the expression of RUNX2, an osteogenesis-associated transcription factor, at $1 \mathrm{~d}$ and $3 \mathrm{~d}$ (Figure 3(a)). Interestingly, the EMD-induced RUNX2 expression was also significantly downregulated by NAMPT, which reached significance at $1 \mathrm{~d}$ (Figure 3(a)). Furthermore, treatment of cells with EMD for $14 \mathrm{~d}$ caused a pronounced calcium accumulation in cell cultures, as determined by alizarin red $S$ staining (Figures 3(b) and 3(c)). When cells were simultaneously treated with EMD and NAMPT, the calcium accumulation was significantly reduced as compared to EMD-stimulated cultures in the absence of NAMPT (Figures 3(b) and 3(c)).

3.4. Effects of NAMPT on EMD-Induced Wound Healing. NAMPT also caused a dose-dependent inhibition of the EMD-stimulated wound healing (Figure 4(a)). The EMDinduced wound closure was significantly reduced by $100 \mathrm{ng} /$ $\mathrm{mL}$ of NAMPT and even more pronounced by $300 \mathrm{ng} / \mathrm{mL}$ of NAMPT at 3, 4, and $5 \mathrm{~d}$, whereas $30 \mathrm{ng} / \mathrm{mL}$ of NAMPT had only a significantly inhibitory effect at $5 \mathrm{~d}$ (Figure $4(\mathrm{a})$ ).

3.5. Effects of NAMPT on BMPRs and TGF $\beta$ Rs in the Presence and Absence of EMD. At least some actions of EMD seem to be mediated by BMP or TGF $\beta$ because EMD 


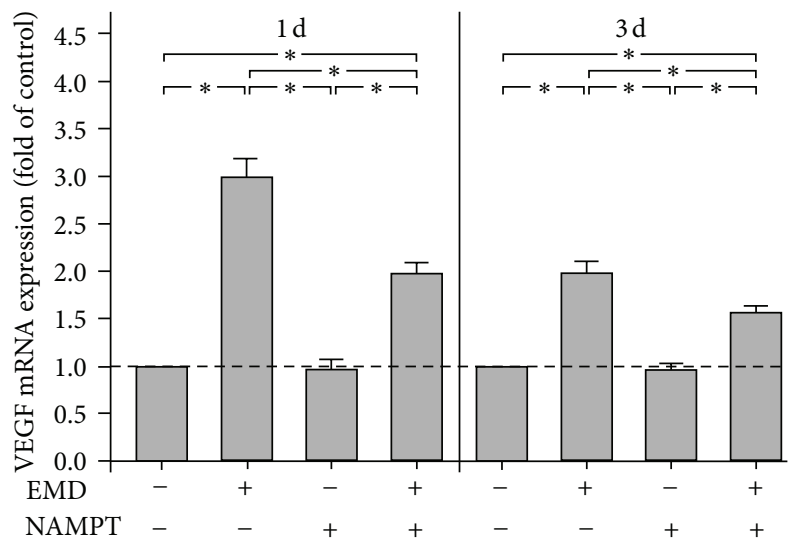

(a)

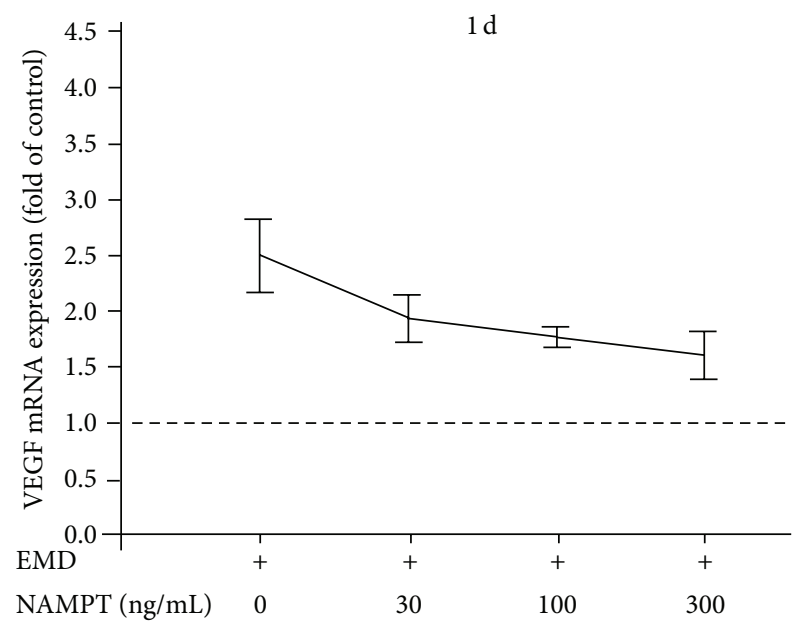

(c)

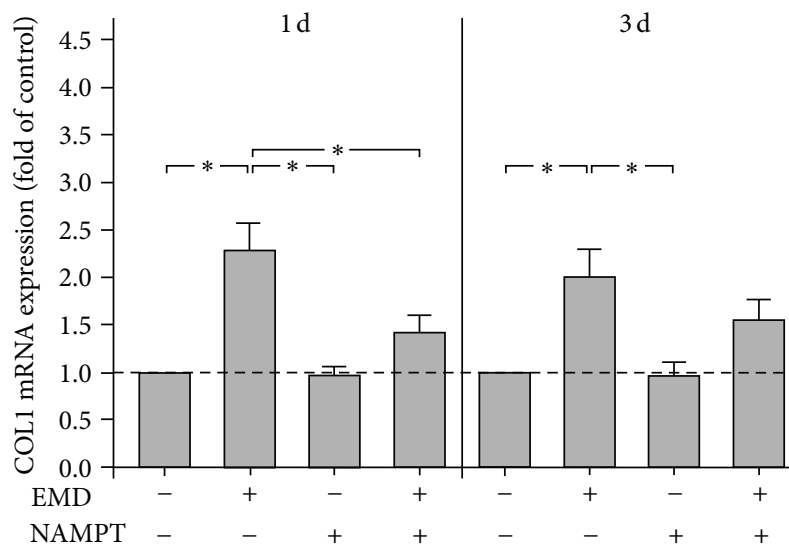

(e)

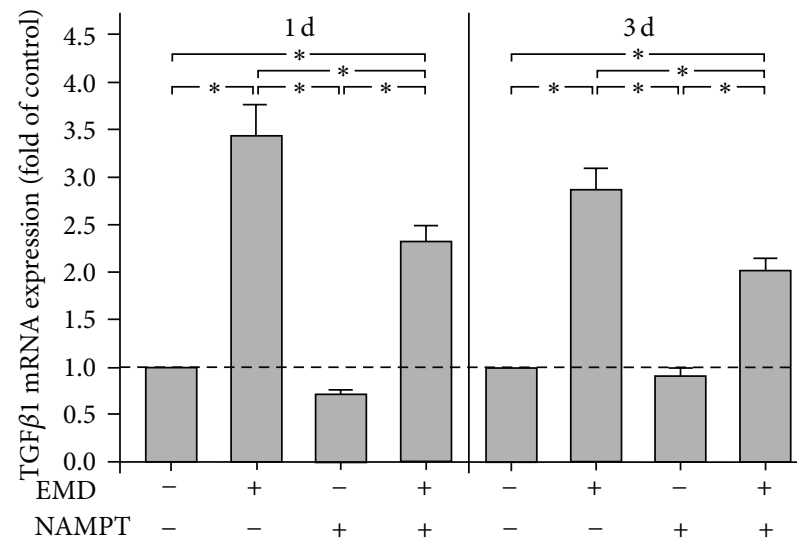

(b)

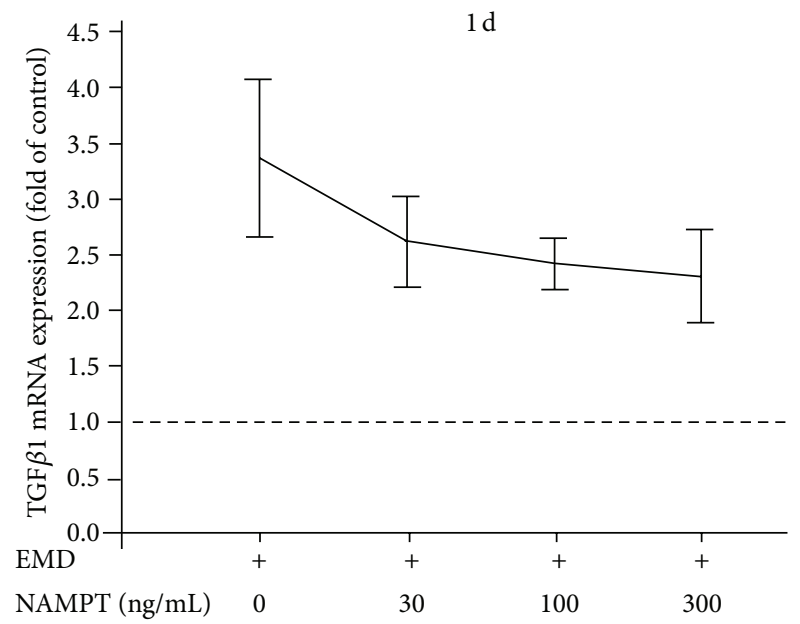

(d)

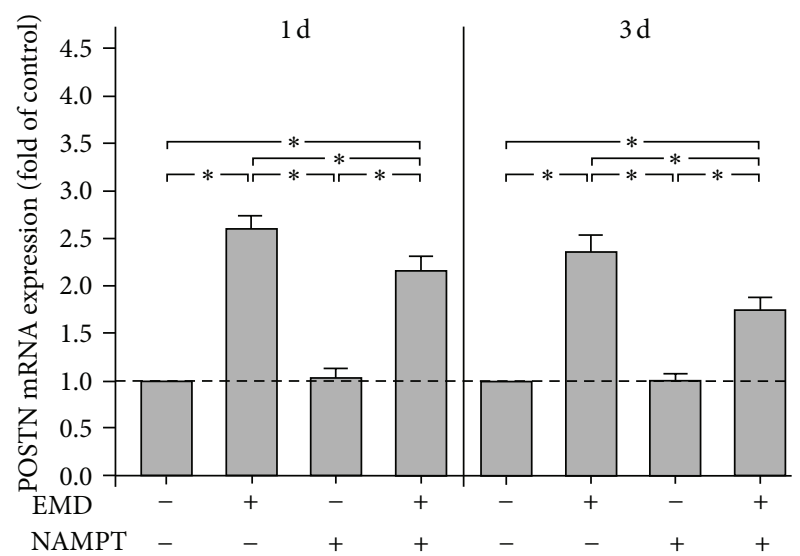

(f)

FIGURE 2: Effect of EMD on the VEGF (a), TGF $\beta 1$ (b), COL1 (e), and POSTN (f) mRNA expressions in the presence and absence of NAMPT $(100 \mathrm{ng} / \mathrm{mL})$ at $1 \mathrm{~d}$ and $3 \mathrm{~d}$. Untreated cells served as control. All experiments were performed in triplicate and repeated at least twice. Mean $\pm \operatorname{SEM}(n=18) ;{ }^{*}$ significant $(P<0.05)$ difference between groups. Effect of various concentrations $(0,30,100$, and $300 \mathrm{ng} / \mathrm{mL})$ of NAMPT on the VEGF (c) and TGF $\beta 1$ (d) mRNA expressions in EMD-treated cells at $1 \mathrm{~d}$. All experiments were performed in triplicate and repeated at least twice. Mean $\pm \operatorname{SEM}(n=9)$. 


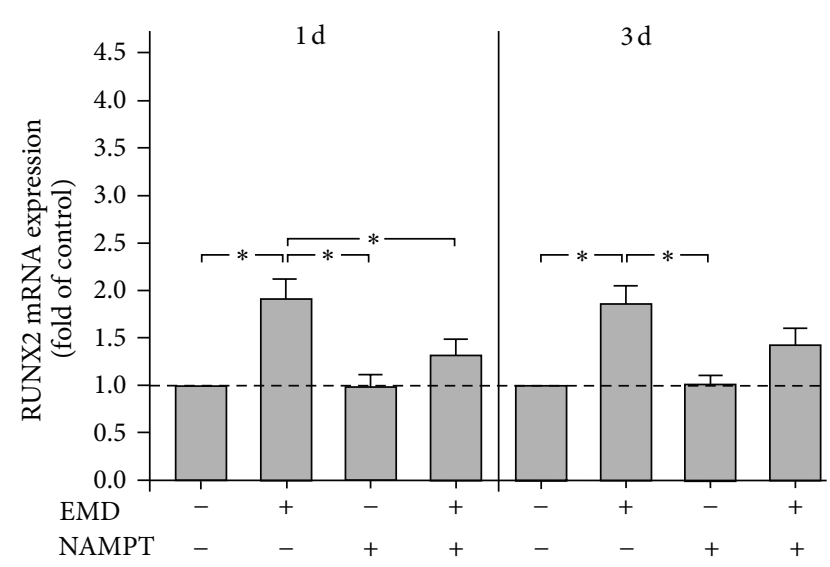

(a)
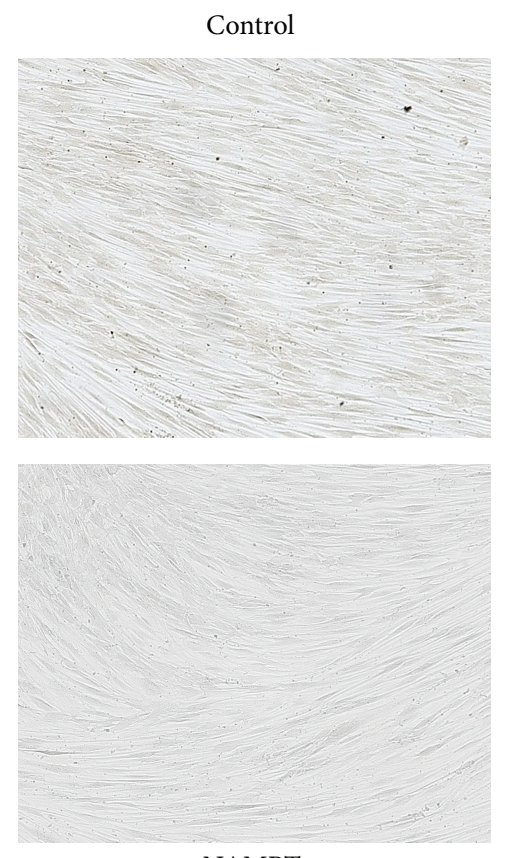

NAMPT

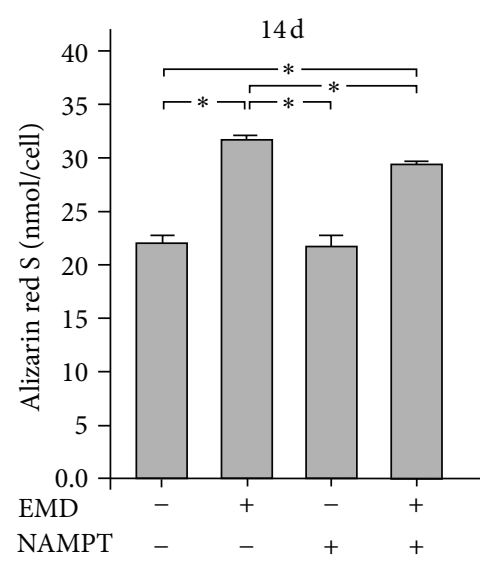

(b)
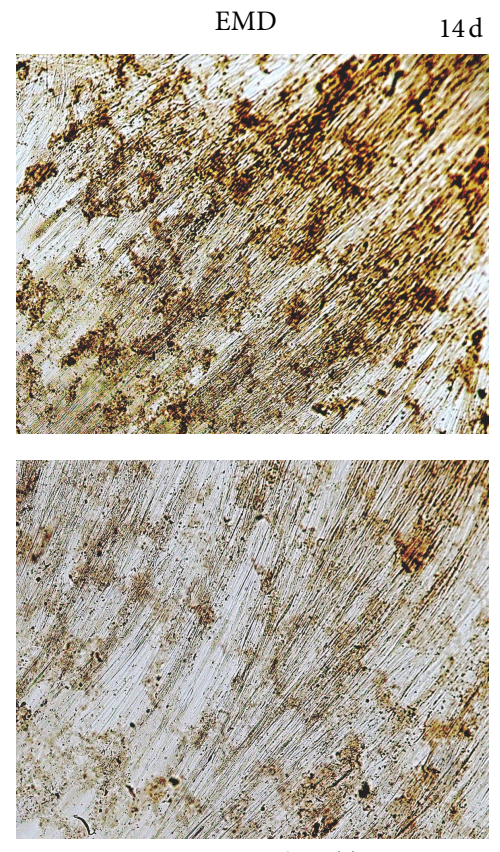

$\mathrm{EMD}+\mathrm{NAMPT}$

(c)

Figure 3: Effect of EMD on the RUNX2 (a) mRNA expression in the presence and absence of NAMPT (100 ng/mL) at $1 \mathrm{~d}$ and $3 \mathrm{~d}$. Untreated cells served as control. All experiments were performed in triplicate and repeated at least twice. Mean \pm SEM $(n=18) ;{ }^{*}$ significant $(P<0.05)$ difference between groups. Effect of EMD on the calcium accumulation in the presence and absence of NAMPT (100 ng/mL) in cultures of PDL cells ((b) and (c)). Untreated cells served as control. The calcium accumulation was analysed by alizarin red S staining, visualized by microscopy (c), and quantified by elution with cetylpyridinium chloride (b) at $14 \mathrm{~d}$. All experiments were performed in triplicate and repeated at least twice. Mean $\pm \operatorname{SEM}(n=12) ;{ }^{*}$ significant $(P<0.05)$ difference between groups. Images from one representative donor are shown.

has been shown to possess BMP- and TGF $\beta$-like activity and, additionally, to upregulate these molecules in periodontal cells. We therefore also examined the effects of NAMPT on BMPRs and TGF $\beta$ Rs. As shown in Figure 4(b), EMD increased significantly the constitutive expression of BMPR1A, BMPR1B, BMPR2, and TGF $\beta$ R2 at $1 \mathrm{~d}$. However, NAMPT caused a significant downregulation of the EMDstimulated expression of these receptors at this time point (Figure 4(b)). Similar results were found for $3 \mathrm{~d}$ (data not shown). In the absence of EMD, a significant inhibition by NAMPT was only found for BMPR1A (Figure 4(b)).
3.6. Inhibition of SMAD Signaling by NAMPT in EMDTreated Cells. Next, we sought to unravel intracellular mechanisms, whereby NAMPT abrogates regeneration-promotive actions of EMD. As shown in Figure 5(a), EMD caused a pronounced accumulation of SMAD1/5/8 in the nucleus of EMD-treated cells at $60 \mathrm{~min}$. However, in the presence of NAMPT, this EMD-stimulated nuclear translocation of SMAD1/5/8 was reduced. In the absence of EMD, no obvious effect of NAMPT on the SMAD1/5/8 nuclear translocation was observed (Figure 5(a)). Further experiments revealed that EMD stimulated the phosphorylation of SMAD1/5/8 in 


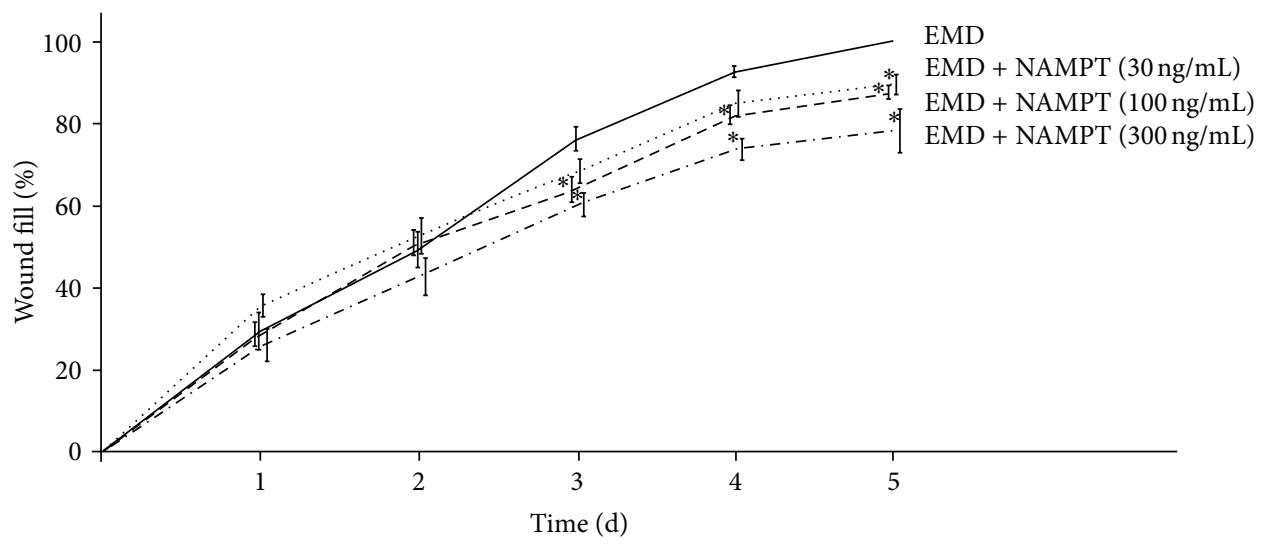

(a)

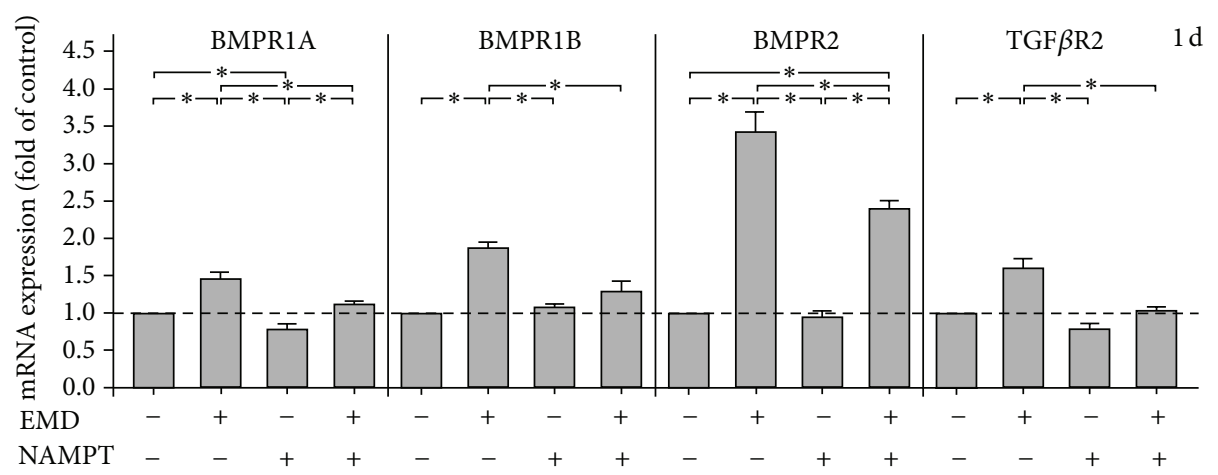

(b)

Figure 4: Effect of various concentrations $(0,30,100$, and $300 \mathrm{ng} / \mathrm{mL})$ of NAMPT on the EMD-induced PDL cell wound fill rate (a). The wound closure, that is, the percentage of fill of the initially cell free zones created by wounding, were analysed over $5 \mathrm{~d}$. All experiments were performed in triplicate and repeated at least twice. Mean $\pm \operatorname{SEM}(n=12) ;{ }^{*}$ significantly $(P<0.05)$ different from EMD-treated cells in the absence of NAMPT. Effect of EMD on the expression of BMPR1A, BMPR1B, BMPR2 and TGF $\beta$ R2 in the presence and absence of NAMPT $(100 \mathrm{ng} / \mathrm{mL})$ at $1 \mathrm{~d}(\mathrm{~b})$. Untreated cells served as control. All experiments were performed in triplicate and repeated at least twice. Mean \pm SEM $(n=18) ;{ }^{*}$ significant $(P<0.05)$ difference between groups.

a time-dependent manner, as evidenced by immunoblotting (Figure 5(b)). As shown in Figure 5(c), the EMD-stimulated SMAD1/5/8 phosphorylation was inhibited in the presence of NAMPT.

\section{Discussion}

The present study demonstrates for the first time that regeneration-promotive actions of EMD on a great number of PDL cell functions critical for periodontal regeneration are jeopardized by NAMPT. The findings of this study suggest that increased levels of NAMPT, as found in obesity and periodontal inflammation, may compromise the regenerative capacity of PDL cells and, thereby, periodontal healing in the presence of EMD.

NAMPT abrogated the stimulatory effects of EMD on VEGF and TGF $\beta 1$, COL1, in vitro wound healing, and osteogenic differentiation. VEGF is an essential growth factor, which supports wound healing by its regulatory effects on vascular permeability, influx of inflammatory cells into the site of injury, migration and proliferation of preexisting endothelial cells, and the recruitment of marrow-derived endothelial progenitor cells to the local wound site [45]. In addition, VEGF seems to play an important role in the modulation of bone remodeling by attracting endothelial cells and osteoclasts and by stimulating osteoblast differentiation [46]. $\mathrm{TGF} \beta$, another important growth factor, comprises three isoforms and also promotes wound healing like VEGF. TGF $\beta 1$ supports migration of wound keratinocytes and, thereby, successful reepithelialization [47]. Moreover, it induces fibroblasts to deposit new extracellular matrix proteins, which promotes cell and vascular in-growth [48]. In addition to growth factors, matrix molecules, such as COL1 and POSTN, are also critical for periodontal homeostasis and healing. Like COL1, POSTN is also strongly expressed in the human PDL and regulates cell-matrix interactions as well as cell adhesion, proliferation, and differentiation $[49,50]$. Furthermore, periostin also aids to disperse mechanical forces applied to the PDL $[50,51]$. Interestingly, NAMPT also counteracted the stimulatory effects of EMD on the in vitro wound healing. Following periodontal treatment, periodontal wounds need to be repopulated with cells to achieve periodontal healing [52]. When EMD-treated cells were exposed to NAMPT, the wound closure was dose-dependently delayed, indicating that 

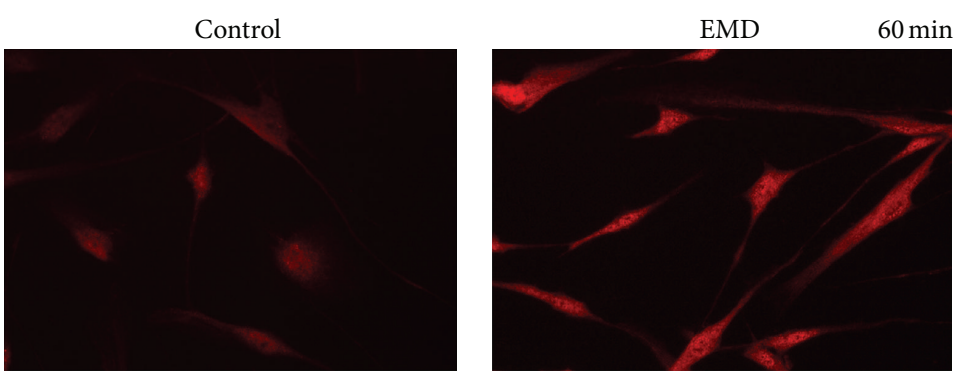

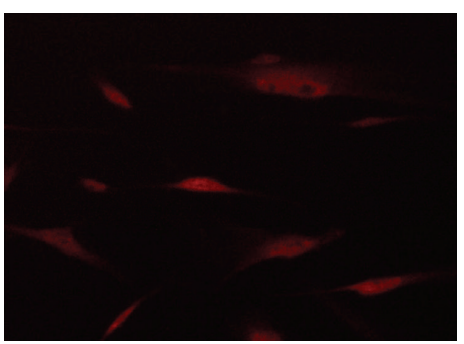

NAMPT

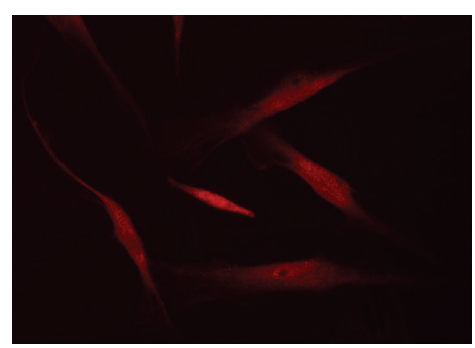

$\mathrm{EMD}+\mathrm{NAMPT}$

(a)

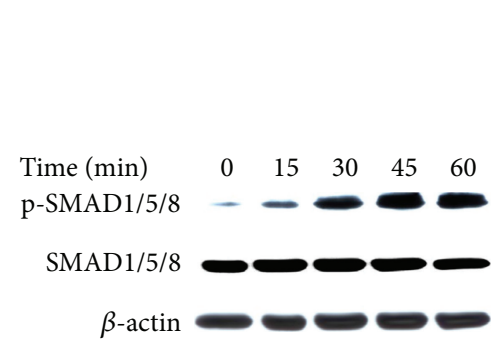

(b)

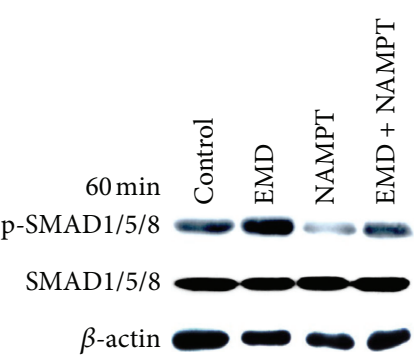

(c)

Figure 5: Effect of EMD on the nuclear translocation of SMAD1/5/8 in the presence and absence of NAMPT (100 ng/mL) at $60 \mathrm{~min}$, as determined by immunofluorescence (a). Untreated cells served as control. Stimulation of SMAD1/5/8 phosphorylation by EMD over 60 min, as analyzed by immunoblotting (b). Effect of EMD on SMAD1/5/8 phosphorylation in the presence and absence of NAMPT (100 ng/mL) at $60 \mathrm{~min}$, as examined by immunoblotting (c). All experiments were performed in triplicate and repeated at least twice. Images and blots from one representative donor are shown.

NAMPT may also inhibit critical cell functions, such as proliferation and migration, under regenerative conditions. PDL cells can acquire an osteoblastic phenotype, and a number of studies have proven that EMD stimulates expression of osteogenesis-associated factors, such as RUNX2, and calcium deposition, an early marker of matrix mineralization, from PDL cells [14]. As expected, EMD upregulated RUNX2 and induced calcium deposition in the present study. In the presence of NAMPT, the stimulatory effects of EMD on these osteogenesis-related processes were reduced. Although NAMPT inhibited significantly the EMD-induced RUNX2 and collagen expressions at 1 day, the inhibitory effects of NAMPT did not reach significance at 3 days due to the pronounced standard deviations. However, including a higher number of donors in these experiments might have resulted in statistically significant changes also at 3 days. Nevertheless, our findings suggest that NAMPT interferes with both the EMD-induced effects on both periodontal soft and hard tissue regeneration.
We also sought to unravel the mechanisms, whereby NAMPT modulates the actions of EMD. Fractions of EMD contain BMP- and TGF $\beta$-like activity and EMD also upregulates BMP and TGF $\beta$ in periodontal cells [16-19]. Therefore, it is thought that beneficial effects of EMD on periodontal regeneration are mediated, at least in part, by these factors. We therefore studied whether NAMPT regulates the expression of their receptors as a possible mechanism, whereby NAMPT may modulate the actions of EMD. BMP binds to BMPR1, upon which BMPR2 is recruited into the complex, or binds to a preformed complex of BMPR1 and BMPR2, which triggers the activation of SMAD and non-SMAD pathways [21]. Following binding of TGF $\beta$ to TGF $\beta$ R2, TGF $\beta$ R1 is recruited into a heterotetrameric receptor complex and then phosphorylated on serine residues by TGF $\beta$ R2, which also finally results in the activation of the SMAD signaling pathway [20]. As shown in the present and our previous studies, PDL cells express receptors for BMP and TGF $\beta$ [2426]. EMD increased the constitutive expression of BMPRs 
and TGF $\beta$ Rs, and this EMD-stimulated receptor upregulation was inhibited by NAMPT. These findings suggest that NAMPT can regulate actions of EMD also at receptor level, as it has recently been shown for interleukin- $1 \beta$ and biomechanical forces [24-26].

Furthermore, we sought to identify intracellular mechanisms, whereby the stimulatory effects of EMD are modulated by NAMPT. Our experiments revealed that the inhibition of the EMD-induced VEGF and TGF $\beta 1$ upregulation by NAMPT was JNK-dependent. Moreover, NAMPT inhibited the EMD-stimulated phosphorylation of SMADs and, additionally, inhibited their nuclear translocation. Further experiments are needed to clarify how JNK interferes with SMAD signaling and whether additional signaling pathways are involved.

The present study also confirms our previous studies on the harmful effects of inflammatory signals on regenerative periodontal healing [24-26]. Moreover, in the present study, we provide original evidence that also systemic factors, such as NAMPT, whose levels are increased in obesity, metabolic syndrome, and diabetes mellitus, may interfere with periodontal healing. Although PDL cells are of utmost importance in periodontal regenerative healing, in a clinical setting, additional cells, such as inflammatory cells, keratinocytes, gingival fibroblasts, and osteo- and cementoblasts, are involved. Further studies should examine whether NAMPT also affects these cells under normal and regenerative conditions. Moreover, in addition to NAMPT, the levels of other adipokines, such as leptin, resistin, and adiponectin, are altered in obesity and periodontal inflammation [5356]. Future studies should therefore focus on the regulation of periodontal cells and their regenerative capacity by these adipokines.

In summary, the present study shows for the first time that beneficial effects of EMD on a number of PDL cell functions critical for periodontal regeneration are counteracted by NAMPT. Enhanced levels of NAMPT, as found in obesity and periodontal inflammation, may compromise the regenerative capacity of PDL cells and, thereby, regenerative periodontal healing in the presence of EMD.

\section{Conflict of Interests}

The authors declare that there is no conflict of interests regarding the publication of this paper.

\section{Acknowledgments}

We would like to thank Professor Stephan Baader, Professor Dieter Fürst, PD Dr. Jochen Winter, Dr. Svenja Memmert, and Ms. Ramona Hömig for their great support. This study was supported by a Grant from the German Research Foundation (Clinical Research Unit 208/TP4) and the Medical Faculty of the University of Bonn.

\section{References}

[1] B. L. Pihlstrom, B. S. Michalowicz, and N. W. Johnson, "Periodontal diseases," The Lancet, vol. 366, no. 9499, pp. 1809-1820, 2005.
[2] L. Sbordone and C. Bortolaia, "Oral microbial biofilms and plaque-related diseases: microbial communities and their role in the shift from oral health to disease," Clinical Oral Investigations, vol. 7, no. 4, pp. 181-188, 2003.

[3] D. N. Tatakis and P. S. Kumar, "Etiology and pathogenesis of periodontal diseases," Dental Clinics of North America, vol. 49, no. 3, pp. 491-516, 2005.

[4] T. Yucel-Lindberg and T. Båge, "Inflammatory mediators in the pathogenesis of periodontitis," Expert Reviews in Molecular Medicine, vol. 15, p. e7, 2013.

[5] J. M. Albandar, "Commentary: underestimation of periodontitis in nhanes surveys," Journal of Periodontology, vol. 82, no. 3, pp. 337-341, 2011.

[6] T. Beikler and T. F. Flemmig, "Oral biofilm-associated diseases: trends and implications for quality of life, systemic health and expenditures," Periodontology 2000, vol. 55, no. 1, pp. 87-103, 2011.

[7] J. Suvan, F. D’Aiuto, D. R. Moles, A. Petrie, and N. Donos, "Association between overweight/obesity and periodontitis in adults. A systematic review," Obesity Reviews, vol. 12, no. 501, pp. e381-e404, 2011.

[8] G. J. Seymour, P. J. Ford, M. P. Cullinan, S. Leishman, and K. Yamazaki, "Relationship between periodontal infections and systemic disease," Clinical Microbiology and Infection, vol. 13, no. 4, pp. 3-10, 2007.

[9] L. J. A. Heitz-Mayfield, "How effective is surgical therapy compared with nonsurgical debridement?" Periodontology 2000, vol. 37, pp. 72-87, 2005.

[10] S. Garrett, "Periodontal regeneration around natural teeth," Annals of Periodontology, vol. 1, no. 1, pp. 621-666, 1996.

[11] M. K. McGuire and D. L. Cochran, "Evaluation of human recession defects treated with coronally advanced flaps and either enamel matrix derivative or connective tissue. Part 2. Histological evaluation," Journal of Periodontology, vol. 74, no. 8, pp. 1126-1135, 2003.

[12] A. Sculean, R. Alessandri, R. Miron, G. E. Salvi, and D. D. Bosshardt, "Enamel matrix proteins and periodontal wound healing and regeneration," Clinical Advances in Periodontics, vol. 1, pp. 101-117, 2011.

[13] R. A. Yukna and J. T. Mellonig, "Histologic evaluation of periodontal healing in humans following regenerative therapy with enamel matrix derivative. A 10-case series," Journal of Periodontology, vol. 71, no. 5, pp. 752-759, 2000.

[14] D. D. Bosshardt, "Biological mediators and periodontal regeneration: a review of enamel matrix proteins at the cellular and molecular levels," Journal of Clinical Periodontology, vol. 35, no. 8, pp. 87-105, 2008.

[15] H. M. Grandin, A. C. Gemperli, and M. Dard, "Enamel matrix derivative: a review of cellular effects in vitro and model of molecular arrangement and functioning," Tissue Engineering B, vol. 18, pp. 181-202, 2012.

[16] D. L. Johnson, D. Carnes, B. Steffensen, and D. L. Cochran, "Cellular effects of enamel matrix derivative are associated with different molecular weight fractions following separation by size-exclusion chomatography," Journal of Periodontology, vol. 80, no. 4, pp. 648-656, 2009.

[17] S. Suzuki, T. Nagano, Y. Yamakoshi et al., "Enamel matrix derivative gel stimulates signal transduction of BMP and TGFß," Journal of Dental Research, vol. 84, no. 6, pp. 510-514, 2005. 
[18] K. Okubo, M. Kobayashi, T. Takiguchi et al., "Participation of endogenous IGF-I and TGF- $\beta 1$ with enamel matrix derivativestimulated cell growth in human periodontal ligament cells," Journal of Periodontal Research, vol. 38, no. 1, pp. 1-9, 2003.

[19] M. H. Parkar and M. Tonetti, "Gene expression profiles of periodontal ligament cells treated with enamel matrix proteins in vitro: analysis using cDNA arrays," Journal of Periodontology, vol. 75, no. 11, pp. 1539-1546, 2004.

[20] S. S. Prime, M. Pring, M. Davies, and I. C. Paterson, "TGF$\beta$ signal transduction in oro-facial health and non-malignant disease (part I)," Critical Reviews in Oral Biology and Medicine, vol. 15, no. 6, pp. 324-336, 2004.

[21] C. Sieber, J. Kopf, C. Hiepen, and P. Knaus, "Recent advances in BMP receptor signaling," Cytokine and Growth Factor Reviews, vol. 20, no. 5-6, pp. 343-355, 2009.

[22] H. Inaba, S. Kawai, K. Nakayama, N. Okahashi, and A. Amano, "Effect of enamel matrix derivative on periodontal ligament cells in vitro is deminished by porphyromonas gingivalis," Journal of Periodontology, vol. 75, no. 6, pp. 858-865, 2004.

[23] H. Inaba, M. Tagashira, T. Kanda, T. Ohno, S. Kawai, and A. Amano, "Apple- and hop-polyphenols protect periodontal ligament cells stimulated with enamel matrix derivative from Porphyromonas gingivalis," Journal of Periodontology, vol. 76, no. 12, pp. 2223-2229, 2005.

[24] M. Nokhbehsaim, J. Winter, B. Rath, A. Jäger, S. Jepsen, and J. Deschner, "Effects of enamel matrix derivative on periodontal wound healing in an inflammatory environment in vitro," Journal of Clinical Periodontology, vol. 38, no. 5, pp. 479-490, 2011.

[25] M. Nokhbehsaim, B. Deschner, C. Bourauel et al., "Interactions of enamel matrix derivative and biomechanical loading in periodontal regenerative healing," Journal of Periodontology, vol. 82, no. 12, pp. 1725-1734, 2011.

[26] M. Nokhbehsaim, B. Deschner, J. Winter et al., "Interactions of regenerative, inflammatory and biomechanical signals on bone morphogenetic protein-2 in periodontal ligament cells," Journal of Periodontal Research, vol. 46, no. 3, pp. 374-381, 2011.

[27] M. Nokhbehsaim, B. Deschner, J. Winter et al., "Anti-inflammatory effects of EMD in the presence of biomechanical loading and interleukin-1 $\beta$ in vitro," Clinical Oral Investigations, vol. 16, no. 1, pp. 275-283, 2012.

[28] B. W. Chaffee and S. J. Weston, "Association between chronic periodontal disease and obesity: a systematic review and metaanalysis," Journal of Periodontology, vol. 81, no. 12, pp. 1708-1724, 2010.

[29] L. Nibali, N. Tatarakis, I. Needleman et al., "Clinical review: association between metabolic syndrome and periodontitis: a systematic review and meta-analysis," Journal of Clinical Endocrinology and Metabolism, vol. 98, pp. 913-920, 2013.

[30] N. G. M. Chávarry, M. V. Vettore, C. Sansone, and A. Sheiham, "The relationship between diabetes mellitus and destructive periodontal disease: a meta-analysis," Oral Health \& Preventive Dentistry, vol. 7, no. 2, pp. 107-127, 2009.

[31] P. M. Preshaw, N. Foster, and J. J. Taylor, "Cross-susceptibility between periodontal disease and type 2 diabetes mellitus: an immunobiological perspective," Periodontology 2000, vol. 45, no. 1, pp. 138-157, 2007.

[32] J. Conde, M. Scotece, R. Gómez et al., "Adipokines: biofactors from white adipose tissue. A complex hub among inflammation, metabolism, and immunity," BioFactors, vol. 37, no. 6, pp. 413-420, 2011.
[33] F. Lago, C. Dieguez, J. Gómez-Reino, and O. Gualillo, "Adipokines as emerging mediators of immune response and inflammation," Nature Clinical Practice Rheumatology, vol. 3, no. 12, pp. 716-724, 2007.

[34] Y.-H. Chang, D.-M. Chang, K.-C. Lin, S.-J. Shin, and Y.-J. Lee, "Visfatin in overweight/obesity, type 2 diabetes mellitus, insulin resistance, metabolic syndrome and cardiovascular diseases: a meta-analysis and systemic review," Diabetes/Metabolism Research and Reviews, vol. 27, no. 6, pp. 515-527, 2011.

[35] D. Taskesen, B. Kirel, and T. Us, "Serum visfatin levels, adiposity and glucose metabolism in obese adolescents," Journal of Clinical Research in Pediatric Endocrinology, vol. 4, pp. 76-81, 2012.

[36] L. Q. Zhang, D. P. Heruth, and S. Q. Ye, "Nicotinamide phosphoribosyltransferase in human diseases," Journal of Bioanalysis and Biomedicine, vol. 3, no. 1, pp. 13-25, 2011.

[37] D. Lakkis, N. F. Bissada, A. Saber et al., "Response to periodontal therapy in patients who had weight loss after bariatric surgery and obese counterparts: a pilot study," Journal of Periodontology, vol. 83, pp. 684-689, 2012.

[38] H. Tilg and A. R. Moschen, "Role of adiponectin and $\mathrm{PBEF} /$ visfatin as regulators of inflammation: involvement in obesity-associated diseases," Clinical Science, vol. 114, no. 3-4, pp. 275-288, 2008.

[39] A. R. Moschen, R. R. Gerner, and H. Tilg, "Pre-b cell colony enhancing factor/nampt/visfatin in inflammation and obesityrelated disorders," Current Pharmaceutical Design, vol. 16, no. 17, pp. 1913-1920, 2010.

[40] A. R. Pradeep, N. M. Raghavendra, M. V. R. Prasad, R. Kathariya, S. P. Patel, and A. Sharma, "Gingival crevicular fluid and serum visfatin concentration: their relationship in periodontal health and disease," Journal of Periodontology, vol. 82, no. 9, pp. 1314-1319, 2011.

[41] A. R. Pradeep, N. M. Raghavendra, A. Sharma et al., "Association of serum and crevicular visfatin levels in periodontal health and disease with type 2 diabetes mellitus," Journal of Periodontology, vol. 83, no. 5, pp. 629-634, 2012.

[42] N. M. Raghavendra, A. R. Pradeep, R. Kathariya, A. Sharma, N. S. Rao, and S. B. Naik, "Effect of non-surgical periodontal therapy on gingival crevicular fluid and serum visfatin concentration in periodontal health and disease," Disease Markers, vol. 32, pp. 383-388, 2012.

[43] A. V. Nogueira, M. Nokhbehsaim, S. Eick et al., "Regulation of visfatin by microbial and biomechanical signals in PDL cells," Clinical Oral Investigations, 2013.

[44] M. Nokhbehsaim, S. Eick, A. V. B. Nogueira et al., "Stimulation of MMP-1 and CCL2 by NAMPT in PDL cells," Mediators of Inflammation, vol. 2013, Article ID 437123, 12 pages, 2013.

[45] N. Ferrara, "Role of vascular endothelial growth factor in the regulation of angiogenesis," Kidney International, vol. 56, no. 3, pp. 794-814, 1999.

[46] M. M. L. Deckers, M. Karperien, C. van der Bent, T. Yamashita, S. E. Papapoulos, and C. W. G. M. Löwik, "Expression of vascular endothelial growth factors and their receptors during osteoblast differentiation," Endocrinology, vol. 141, no. 5, pp. 1667-1674, 2000.

[47] Y. Seomun, J.-T. Kim, and C.-K. Joo, "MMP-14 mediated MMP9 expression is involved in TGF-betal-induced keratinocyte migration," Journal of Cellular Biochemistry, vol. 104, no. 3, pp. 934-941, 2008.

[48] P. Sysa, J. J. Potter, X. Liu, and E. Mezey, “Transforming growth factor- $\beta 1$ up-regulation of human $\alpha 1$ (I) collagen is mediated by 
Spl and Smad2 transacting factors," DNA and Cell Biology, vol. 28, no. 9, pp. 425-434, 2009.

[49] D. W. Hamilton, "Functional role of periostin in development and wound repair: implications for connective tissue disease," Journal of Cell Communication and Signaling, vol. 2, no. 1-2, pp. 9-17, 2008.

[50] W. Wen, E. Chau, L. Jackson-Boeters, C. Elliott, T. D. Daley, and D. W. Hamilton, "TGF- $\beta 1$ and FAK regulate periostin expression in PDL fibroblasts," Journal of Dental Research, vol. 89, no. 12, pp. 1439-1443, 2010.

[51] H. F. Rios, D. Ma, Y. Xie et al., "Periostin is essential for the integrity and function of the periodontal ligament during occlusal loading in mice," Journal of Periodontology, vol. 79, no. 8, pp. 1480-1490, 2008.

[52] I. Aukhil, "Biology of wound healing," Periodontology 2000, vol. 22, no. 1, pp. 44-50, 2000.

[53] H. Inadera, "The usefulness of circulating adipokine levels for the assessment of obesity-related health problems," International Journal of Medical Sciences, vol. 5, no. 5, pp. 248-262, 2008.

[54] R. B. Johnson and F. G. Serio, "Leptin within healthy and diseased human gingiva," Journal of Periodontology, vol. 72, no. 9, pp. 1254-1257, 2001.

[55] B. V. Karthikeyan and A. R. Pradeep, "Leptin levels in gingival crevicular fluid in periodontal health and disease," Journal of Periodontal Research, vol. 42, no. 4, pp. 300-304, 2007.

[56] T. Saito, N. Yamaguchi, Y. Shimazaki et al., "Serum levels of resistin and adiponectin in women with periodontitis: the hisayama study," Journal of Dental Research, vol. 87, no. 4, pp. 319-322, 2008. 


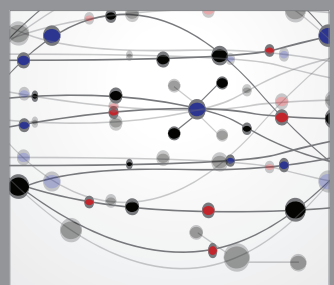

The Scientific World Journal
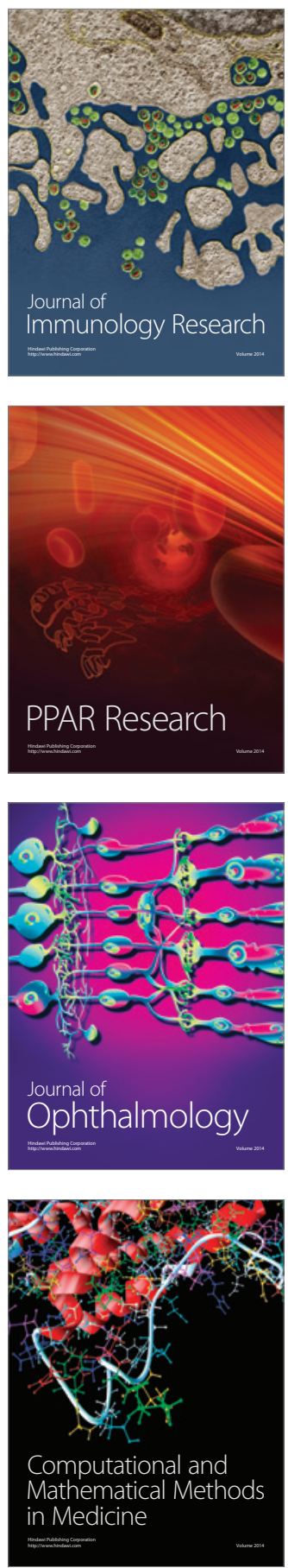

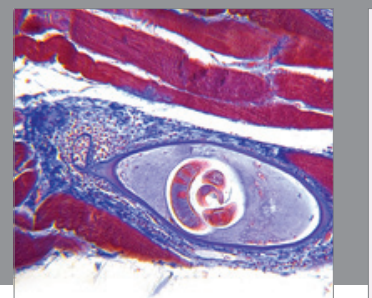

Gastroenterology

Research and Practice
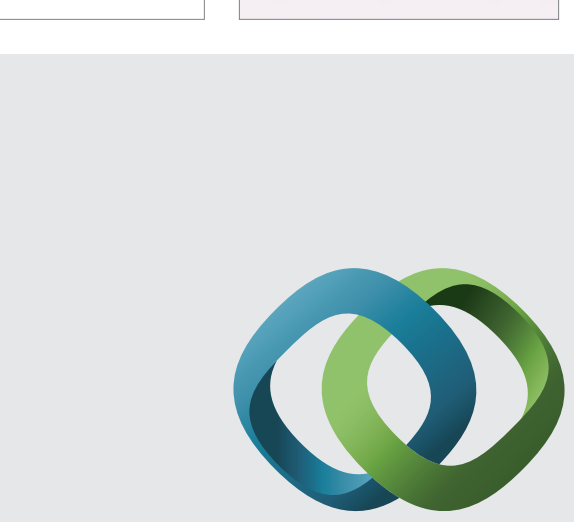

\section{Hindawi}

Submit your manuscripts at

http://www.hindawi.com
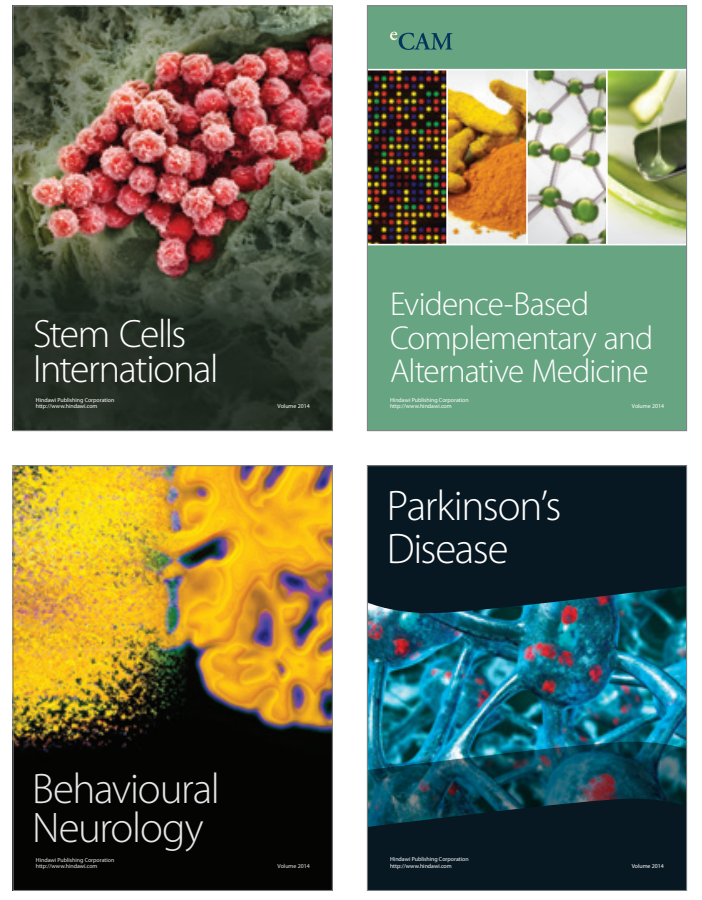
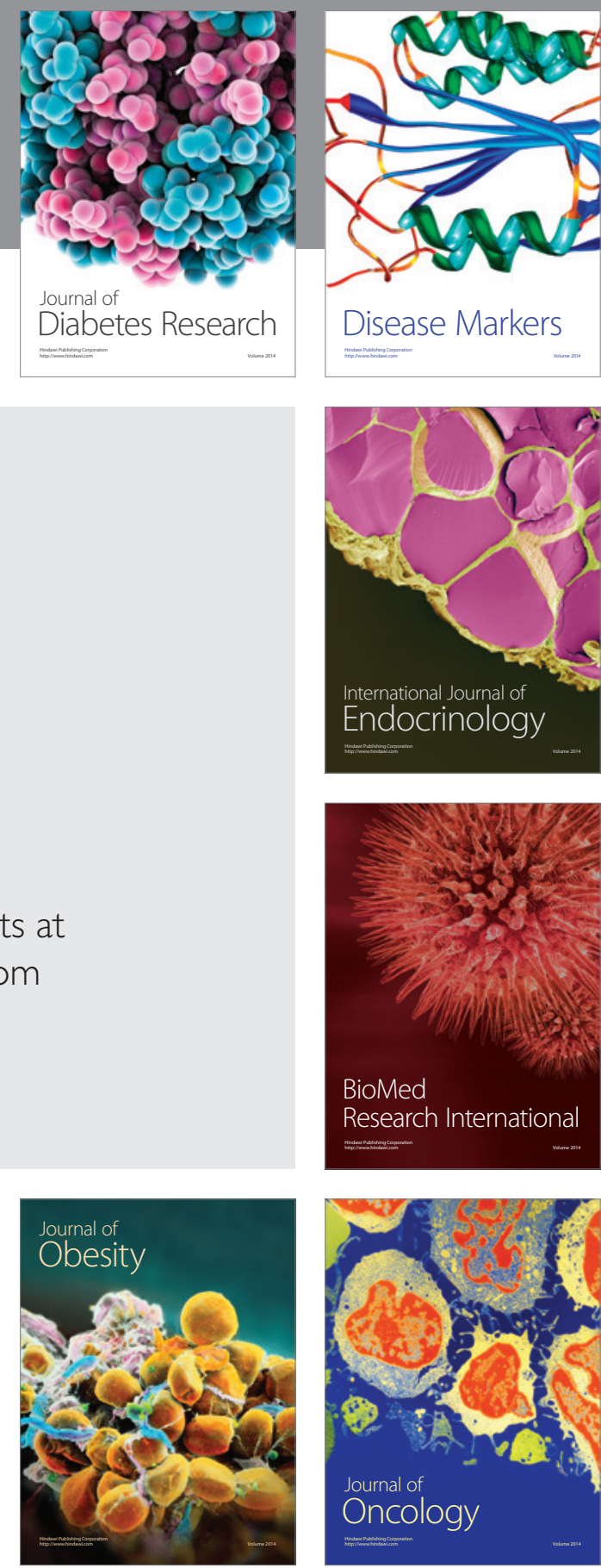

Disease Markers
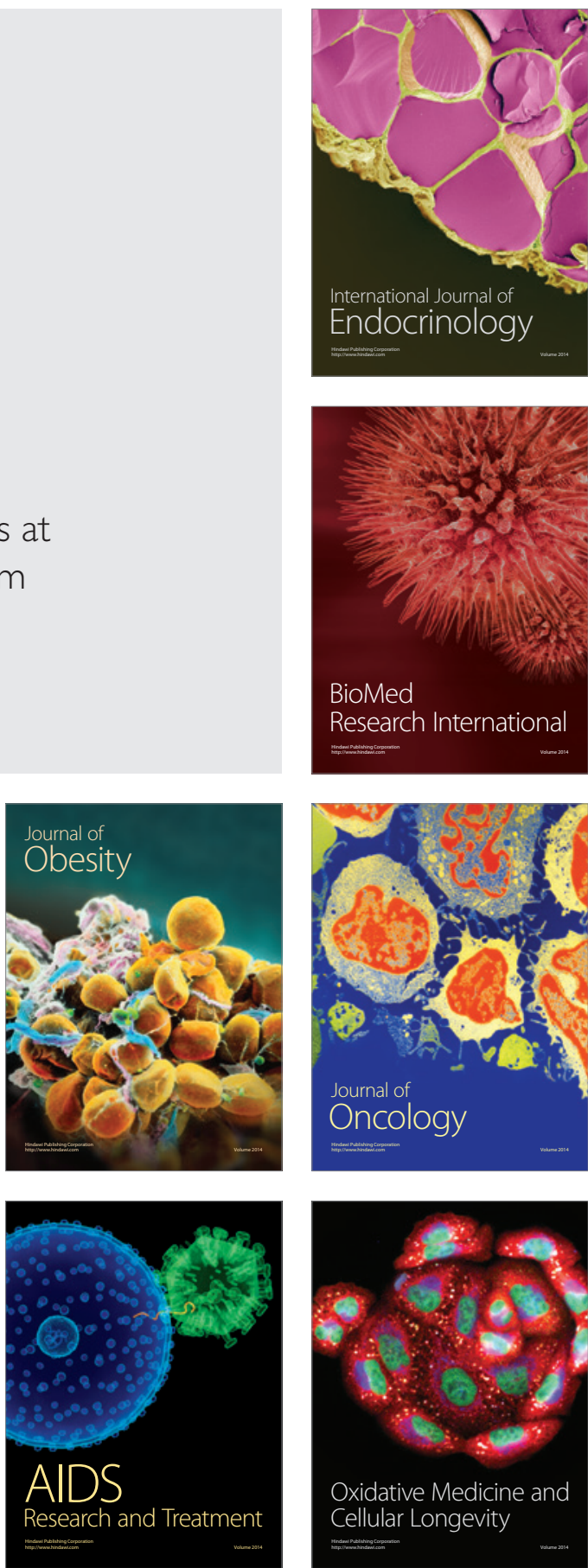